\title{
The Conceptual Framework of Cold Chain for Fishery Products in Indonesia
}

\author{
Pregiwati Pusporini*, Said Salim Dahdah \\ Department of Industrial Engineering, Faculty of Engineering, University of Muhammadiyah Gresik, Gresik, Indonesia
}

Received February 25, 2020; Revised May 20, 2020; Accepted May 31, 2020

Copyright $(2020$ by authors, all rights reserved. Authors agree that this article remains permanently open access under the terms of the Creative Commons Attribution License 4.0 International License

\begin{abstract}
Purpose: The main aim of this research is to determine the main component of cold chain implementation for fishery products in Indonesia. Methodology: Literature review and a deep discussion with expert were employed in this research. A concept of analytical hierarchy process was employed to assess the main component and sub component of cold chain implementation for fishery product in Indonesia. Results: Based on the comparison of the scores of the main component, it can be seen that the aspects of the fish processing industry have the highest value followed by aspects of support industry and government aspects with a value of $0.419 ; 0.359$; and 0.222 , respectively. Meanwhile, the sub component, the fish processing industry it can be seen that the costs for installation and operation occupy the highest score value position that is 0.520 . This shows that fish processing industry emphasizes that the amount of costs they must bear in connection with the implementation of the cold chain concept is a very dominant factor. The second sub component is the consolidation and coordination of all members of the supply chain involved by 0.343 and the third sub component is the availability of experts in the application of the cold chain concept in the field of 0.239. Applications/ Originality/Value: The contribution of this study is prioritization of main component of cold chain framework using AHP as an appropriate formal method. This study is expected has a significant contribution to design a strong collaboration between all stakeholders related to cold chain implementation.
\end{abstract}

Keywords Cold Chain, Perishable, Supply Chain, Collaboration

\section{Introduction}

The fisheries sector is now one of the special concerns of the Indonesian government to optimize the return of its wealth so that it has added value and contributes to state revenues and especially people's welfare. According to data from the Ministry of Maritime Affairs and Fisheries, fisheries production in Indonesia is increasing, from 2011 production of 13.64 million tons rose sharply in the fourth quarter of 2017 to reach a production rate of 23.51 million tons per year. Fish consumption is also known to increase where in 2014 the initial average was $38.14 \mathrm{~kg} / \mathrm{cap} /$ year increasing to $46.49 \mathrm{~kg}$ / cap / year.

Fishery products as one of perishable product need to be treated appropriately to keep the quality. The cold chain system for perishable products must be designed and executed properly, otherwise it causes many losses such as excessive maturing, weight loss, softening, color and texture changes, physical degradation and bruising, and attack by rot and mould. These factors affect freshness, desirability, and marketability.

Indonesian fisheries data which is increasing every year is an opportunity and challenge that must be addressed carefully. Opportunities in the fisheries sector have the potential to be a great contributor to national economic development. But at the same time, there are challenges, namely the perishable nature of the fish, so special handling is needed to keep the fish fresh and have high quality. This handling effort is needed both on board fishing vessels, in aquaculture ponds, when landed at port, in fish processing units, and when distributed. The government should be involved related to provide supporting facilities such as plant and cold storage or air blast freezer and also sea transportation.

Even a concept of cold chain is necessary and must be applied for the perishable products including fishery products to ensure the quality of the products, there are some highlighted that have to be concerned in fishery business in Indonesia. The percentage of fish losses reach in average 30 percent, $85 \%$ of completing facilities in cold application chain system, high losses against catches around $30 \%$ (average value) due to several things: (a) 
fishing fleet of $85 \%$ dominated by small scale fishermen without equipped with cooling facilities (ice, cool box) and the trip time is quite long because the fishing ground is far away; (b) landing facilities and fish auctions that are not or less meet the standards; (c) no or lack supporting facilities such as ice factories and supplies clean water.

The purpose of this study is to identify the framework of cold chain implementation particularly for fishery product in Indonesia. The contribution of this study is prioritization of main component of cold chain framework using AHP as an appropriate formal method. This study is expected has a significant contribution to design a strong collaboration between all stakeholders related to cold chain implementation in Indonesia.

\section{Literature Review}

Nowadays, the value of loss and wastage of food achieves around one-third of the global production in terms of weight. To deal with the issue of food loss, a better utilization of food resources is needed that can maintain the freshness and quality of food starting from the raw material of food to reach consumers. One method that is widely known today for the management and distribution of food is the concept of cold chain. The term of cold chain can be defined into three perspectives namely, cold chain as a science, cold chain as a technology and cold chain as a process. The meaning of cold chain as a science refers to that this concept needs the understanding both of the chemical and biological processes which related to perishability. The second terminology of cold chain as a technology refers to this concept depending on physical means to ensure suitable temperature circumstances alongside the supply chain. Then the last terminology of cold chain as a process refers to this approach consists a set of tasks have to be performed to arrange, store, transport and monitor temperature sensitive products. The basic elements of a cold chain involve: cooling systems (carrying products or commodities to the proper temperature for processing, storage and transportation), cold storage (providing facilities for the storage of products or commodities over a period of time, while waiting to be transported and distributed), cold transport (having deliveries available to transport products or commodities while keeping steady temperature and humidity environments as well as keeping their quality and freshness), cold processing and distribution (providing facilities for the processing of products or commodities including ensuring sanitary circumstances, consolidating and deconsolidating loads such as boxes and pallets for distribution). Furthermore, the concept of cold supply chain is one method that can be applied to maintain the quality and freshness of perishable products, one of which is fishery products. Many researchers highlighted several factors that affect to inefficient food cold chain implementation as shown in table 1 .

\section{Materials and Method}

This research is a part of a research project with the main aim is to develop a configuration model of traceability system and cold chain for fishery products in Indonesia. This paper concerns on developing the hierarchy of key indicators of cold chain implementation of fishery products. The data is collected based on the literature review and a deep discussion with some stakeholders and expert in fishery business. A literature survey has been done particularly on cold chain concept. Then, a deep discussion and brainstorming with some experts have been conducted. The experts in this research refer to someone who have expertise, knowledge and experience relate to fishery products and fishery business in Indonesia. The analytical hierarchy process is used to determine the value of the weights of each of the main criteria and sub criteria. Analytical hierarchy process is a well-known and the most widely concept of multi criteria decision making (MCDM) tools that have been applied in many different fields in both of manufacturing and service industry (Pusporini, P., \& Vanany, I.,2017; Pusporini, P., \& Vanany, I.,2019). Then, the concept of pairwise comparisons is carried out to determine the weights of each component and sub component. 
Table 1. Key factors for cold chain implementation

\begin{tabular}{cl}
\hline Key factors & \multicolumn{1}{c}{ References } \\
\hline & Ashok et al., 2017; Baert et al., 2012; Duarte Alonso, 2013; Joshi et al., \\
2011; Joshi et al., 2012; Liao et al., 2011; M \& K, 2016; Minten, 2016; \\
Papargyropoulou et al., 2014; Shabani et al., 2012; Sharma, 2015; \\
Shashi et al., 2017; Shukla, 2013)
\end{tabular}

lacks of refrigerated carriers

lack of consciousness about the use of information technology

unavailability of power and water

lack of incorporation

great cost

lack of modern processing and packing method

shortage of expert in food cold chain

inadequate of education of farmers

lack of information sharing

lack of standardization

government regulation
Joshi et al., 2011; Joshi et al., 2012; Shabani et al., 2012; Sharma, 2015; Shukla, 2013)

Ashok et al., 2017; Baert et al., 2012; Joshi et al., 2011; Joshi et al., 2012; Sharma, 2015)

Joshi et al., 2011; Joshi et al., 2012)

Baert et al., 2012; Hsiao \& Huang, 2016; Joshi et al., 2011; Joshi et al., 2012; Shabani et al., 2012; Sharma, 2015; Shashi et al., 2017)

Ashok et al., 2017; Baert et al., 2012; Joshi et al., 2011; Joshi et al., 2012; Kristensen et al., 2016; Liao et al., 2011; M \& K, 2016; Minten, 2016; Papargyropoulou et al., 2014; Shabani et al., 2012; Sharma, 2015; Shukla, 2013;)

Ashok et al., 2017; Baert et al., 2012; Duarte Alonso, 2013; Hsiao \& Huang, 2016; Liao et al., 2011; Papargyropoulou et al., 2014)

Ashok et al., 2017; Joshi et al., 2011; Joshi et al., 2012; Kristensen et al., 2016; Liao et al., 2011; M \& K, 2016; Shabani et al., 2012; Sharma, 2015)

Ashok et al., 2017; Baert et al., 2012; Duarte Alonso, 2013; Hsiao \& Huang, 2016; Joshi et al., 2011; Joshi et al., 2012; Kristensen et al., 2016; Liao et al., 2011; M \& K, 2016; Shabani et al., 2012; Sharma, 2015; Shashi et al., 2017; Shukla, 2013; Smigic et al., 2016; Thakur \& Forås, 2015)

Ashok et al., 2017; Baert et al., 2012; Duarte Alonso, 2013; Hsiao \& Huang, 2016; Joshi et al., 2011; Joshi et al., 2012; Kristensen et al., 2016; Liao et al., 2011; M \& K, 2016; Shabani et al., 2012; Sharma, 2015; Shashi et al., 2017; Thakur \& Forås, 2015)

Ashok et al., 2017; Baert et al., 2012; Joshi et al., 2011; Joshi et al., 2012)

Ashok et al., 2017; Baert et al., 2012; Duarte Alonso, 2013; Joshi et al., 2011; Joshi et al., 2012; M \& K, 2016; Minten, 2016; Shabani et al., 2012; Sharma, 2015; Shashi et al., 2017;)

\section{Result and Discussion}

Based on the literature survey and brainstorming with experts in cold chain concept, there are three main factors of cold chain implementation namely, government, main industry and support industry. Main industry in this research refers to the fish processing industry while support industry (hub industry) refers to the industry that support cold chain implementation such as ice cubes factory, container and cold storage industry.

The government takes an important role in the implementation of cold chain relate to regulation, facilities development and also information system. Government's regulation influence on many aspects such as annual catch quote, monetary policy including interest rate, policy on the use of facilities (fishing gear, ships), licensing policies. These factors have a significant impact to the fisherman and also their capability to provide fish product. For example, the regulation of monetary policy will impact to the financial capability of fisherman to survive in their business relate to how to provide a ship, their maintenance cost, their financial to provide enough fuel and ice, etc.

What is more, in the development of facilities, government plays as a trade facilitation, port facilitation, 
fuel supply, ice supply. For example, how does the government provide appropriate ports and their facilities to support fishery business, how does the government guarantee on the availability of fuel and ice to support the implementation of cold chain.

At the same time, the government takes an important role related to the development of information systems. For example, by using the satellite technology, government provides information relate to on weather prediction, seasonal catch prediction and also stock availability. This information has many beneficial for the fishery business so the fisherman can create an appropriate schedule when they have to catch fishes, in which area and what kind of fish they can get.

The second factor of conceptual framework of cold chain implementation is main industry (fish processing industry). These factors will include transportation, cold storage and ships. Transportation will cover the type of transportation used, reliability, capacity and cost and efficiency. Transportation is an important part of the cold chain concept. An appropriate transportation will guarantee the quality of fishery products and ensure their freshness and safe for consumption when they reach the destination market. The type of transportation used includes the selection and provision of cold storages as well as the selection and supply of ships as their means of transportation. Meanwhile cold storage includes several aspects, for example: how the size (design) of the cold storage (the design influences to the capacity of cold storage), how to design and set the cooling materials, how to guarantee the availability of cooling materials, how to provide enough power in the cold storage to keep the freeze temperature, and also how the total cost that have to be spent as an initial investment to provide appropriate cold storage and their efficiency. Similarly, the type and size of ships used determine their capacity, the cost that have to be provided, efficiency and also their reliability to support cold chain implementation.

Supporting industries refers to industries related to the fish processing industry in the implementation of cold chain concepts such as the existence of an ice factory that will be able to provide and supply ice cubes as a cooling material for storing fishery products. The cold storage rental industry is regarded as a means of storing fishery products and the availability of transportation (containers, trucks) to support the cold chain concept of fishery products.

Based on the three main components, then it can be simplified and divided into several sub components related to the main component. Then, these main components and sub components were constructed into a hierarchical diagram. The three main component and sub components of the implementation of the cold chain concept in fishery products along with the score of each of the main component and sub component based on the results of the analysis of the analytical hierarchy process is shown in Figure 1 below.

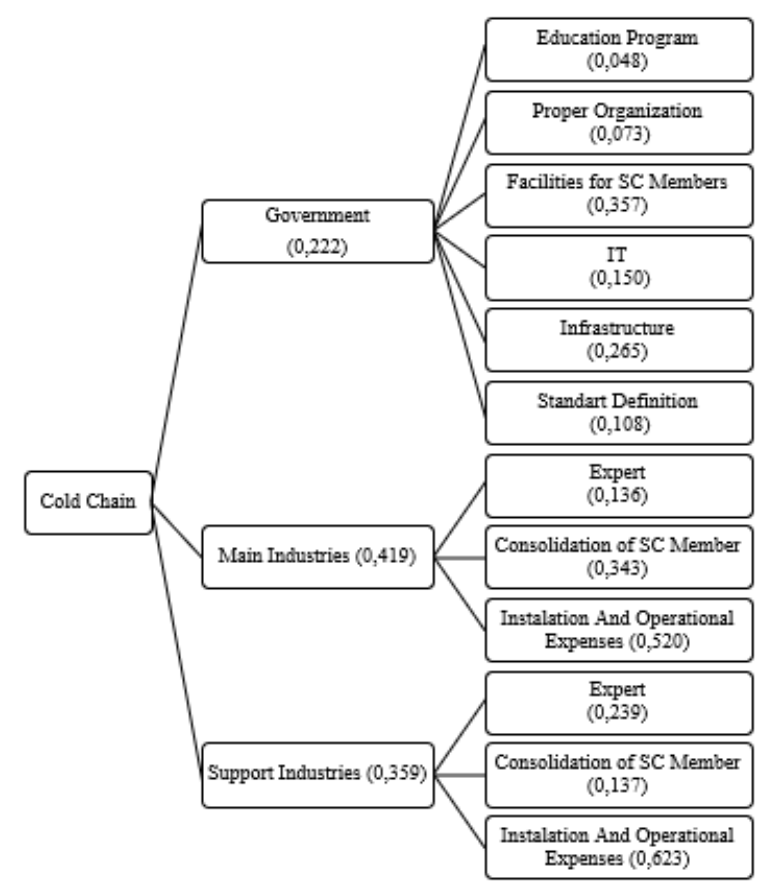

Figure 1. The hierarchy of cold chain implementation

Based on the comparison of the scores of the main component, it can be seen that the aspects of the fish processing industry have the highest value followed by aspects of support industry and government aspects with a value of $0.419 ; 0.359$; and 0.222 , respectively. Whereas in the main sub component, fish processing industry it can be seen that the costs for installation and operation occupy the highest score value position that is 0.520 . This shows that fish processing industry emphasizes that the amount of costs they must bear in connection with the implementation of the cold chain concept is a very dominant factor. The second sub component is the consolidation and coordination of all members of the supply chain involved by 0.343 and the third sub component is the availability of experts in the application of the cold chain concept in the field of 0.239 .

The second component, support industry consists of three sub components, namely the availability of experts, consolidation and costs incurred. Based on these three sub component, it can be seen that the installation and operational expenses also occupies the highest position with the value 0.623 and followed by the expert availability and consolidation of SC members of 0.239 and 0,137 , respectively.

The third component, government are divided into six sub component such as education program, proper organization, facilities, IT, infrastructure and standards. Based on the six sub components, it was found that the facilities achieved the highest score, 0.357 and followed by infrastructure, IT, standards, proper organization and education program with a value of $0.265 ; 0.150 ; 0.108$; $0.073 ; 0.048$ in sequence.

The score values for each of the main component, sub component and the global value of each weight can be seen in the following table 2 . 
Table 2. Local and global weight

\begin{tabular}{ccccc}
\hline Main component & Sub component & score & Local weight & Global weight \\
\hline \multirow{2}{*}{ Government } & Education program & & 0,048 & 0,011 \\
& Proper organization & & 0,073 & 0,016 \\
& Facilities for SC members & 0,222 & 0,357 & 0,079 \\
IT & & 0,150 & 0,033 \\
& Infrastructure & & 0,265 & 0,059 \\
Main industry & Standard definition & & 0,108 & 0,024 \\
& Expert & & 0,136 & 0,057 \\
& Consolidation of SC members & 0,419 & 0,343 & 0,144 \\
& Installation and operational & & 0,520 & 0,218 \\
expenses & & 0,239 & 0,186 \\
Support industry & Expert & & 0,137 & 0,049 \\
& Consolidation of SC members & 0,359 & 0,623 & 0,224 \\
\hline
\end{tabular}

\section{Conclusions}

The key success factor for the cold chain system consists three fundamental factors i.e. government, main industry and support industry. Even a concept of cold chain is necessary and must be applied for the perishable products including fishery products to ensure the quality of the products, there are some highlighted that have to be concerned in fishery business in Indonesia. A strong collaboration and commitment between government, main industry and support industry is needed to provide the availability of cold chain infrastructure and facilities such as cooling facilities, ice factories, supplies clean water. Some programs need to be set as a target for the implementation of cold chain for fishery products. The priority of these programs on how to accelerate implementation of cold chain start from on board, introduction the use of cooling material at landing center, facilitate port with cold chain support (ice factories, cold storage), chilling room and clean water supply). Lastly, the consideration of the availability of laboratory facility processing and quality testing on port is to deal with import process requirements and also to meet with a quality certificate nationally and internationally standard.

\section{Acknowledgement}

This research is supported by the Directorate of Research and Higher Education of Indonesia and the University of Muhammadiyah Gresik.

\section{REFERENCES}

[1] Ashok, A., Brison, M., \& LeTallec, Y. (2017). Improving cold chain systems: Challenges and solutions. Vaccine, 35(17), 2217-2223. doi:https://doi.org/10.1016/j.vaccine.20 16.08.045

[2] Baert, K., Van Huffel, X., Jacxsens, L., Berkvens, D., Diricks, H., Huyghebaert, A., \& Uyttendaele, M. (2012). Measuring the perceived pressure and stakeholders' response that may impact the status of the safety of the food chain in Belgium. Food Research International, 48(1), 257-264. doi: https://doi.org/10.1016/j.foodres.2012.04.005

[3] Duarte Alonso, A. (2013). Investigating farmers' involvement in value-added activities. British Food Journal, 115(10), 1407-1427. doi: 10.1108/BFJ-04-2011-0104

[4] Hsiao, H.-I., \& Huang, K.-L. (2016). Time-temperature transparency in the cold chain. Food Control, 64, 181-188. doi: https://doi.org/10.1016/j.foodcont.2015.12.020

[5] Joshi, R., Banwet, D. K., \& Shankar, R. (2010). Consumer link in cold chain: Indian scenario. Food Control, 21(8), 1137-1142. doi: https://doi.org/10.1016/j.foodcont.2010.01. 008

[6] Joshi, R., Banwet, D. K., \& Shankar, R. (2011). A Delphi-AHP-TOPSIS based benchmarking framework for performance improvement of a cold chain. Expert Systems with Applications, 38(8), 10170-10182. doi: https://doi.org/10.1016/j.eswa.2011.02.072

[7] Joshi, R., Banwet, D. K., Shankar, R., \& Gandhi, J. (2012). Performance improvement of cold chain in an emerging economy. Production Planning \& Control, 23(10-11), 817-836. doi: 10.1080/09537287.2011.642187

[8] Kristensen, D. D., Lorenson, T., Bartholomew, K., \& Villadiego, S. (2016). Can thermostable vaccines help address cold-chain challenges? Results from stakeholder interviews in six low- and middle-income countries. Vaccine, 34(7), 899-904. doi: https://doi.org/10.1016/j.vaccine.2016. 01.001

[9] Liao, P.-A., Chang, H.-H., \& Chang, C.-Y. (2011). Why is the food traceability system unsuccessful in Taiwan? Empirical evidence from a national survey of fruit and vegetable farmers. Food Policy, 36(5), 686-693. doi: 
https://doi.org/10.1016/j.foodpol.2011.06.010

[10] M, B., \& K, A. (2016). Modeling the causes of food wastage in Indian perishable food supply chain. Resources, Conservation and Recycling, 114, 153-167. doi: https://doi.org/10.1016/j.resconrec.2016.07.016

[11] Minten, B. (2016). Wastage in Food Value Chains in Developing Countries: Evidence from the Potato Sector in Asia (D. Hu \& K. A. S. Murshid, Trans.). In T. Reardon (Ed.), Food Security in a Food Abundant World (Vol. 16, pp. 225-238): Emerald Group Publishing Limited.

[12] Papargyropoulou, E., Lozano, R., K. Steinberger, J., Wright, N., \& Ujang, Z. b. (2014). The food waste hierarchy as a framework for the management of food surplus and food waste. Journal of Cleaner Production, 76, 106-115. doi: https://doi.org/10.1016/j.jclepro.2014.04.020

[13] Pusporini, P., \& Vanany, I. (2017, 10-13 Dec. 2017). Challenges in implementing cleaner production: Barriers and strategies in the Indonesian seafood processing industry. Paper presented at the 2017 IEEE International Conference on Industrial Engineering and Engineering Management (IEEM).

[14] Pusporini, P., \& Vanany, I. (2019). Selection process of sustainable production indicators using eco-quality function deployment. IOP Conference Series: Materials Science and Engineering, 528, 012019. doi: 10.1088/1757-899x/528/1/0 12019
[15] Shabani, A., Saen, R. F., \& Torabipour, S. M. R. (2012). A new benchmarking approach in Cold Chain. Applied Mathematical Modelling, 36(1), 212-224. doi: https://doi.org/10.1016/j.apm.2011.05.051

[16] Sharma, S. (2015). Analysis of operating effectiveness of a cold chain model using Bayesian networks. Business Process Management Journal, 21(4), 722-742. doi: 10.1108/BPMJ-10-2014-0105

[17] Shashi, Singh, R., \& Shabani, A. (2017). Value-Adding Practices in Food Supply Chain: Evidence from Indian Food Industry. Agribusiness, 33(1), 116-130. doi: 10.1002/agr.21 478

[18] Shukla, M. (2013). Agri-fresh produce supply chain management: a state-of-the-art literature review. International Journal of Operations \&amp; Production Management, 33(2), 114-158. doi:10.1108/0144357131129 5608

[19] Smigic, N., Djekic, I., Martins, M. L., Rocha, A., Sidiropoulou, N., \& Kalogianni, E. P. (2016). The level of food safety knowledge in food establishments in three European countries. Food Control, 63, 187-194. doi: https://doi.org/10.1016/j.foodcont.2015.11.017

[20] Thakur, M., \& Forås, E. (2015). EPCIS based online temperature monitoring and traceability in a cold meat chain. Computers and Electronics in Agriculture, 117, 22-30. doi: https://doi.org/10.1016/j.compag.2015.07.006 